\title{
Microbially-mediated indirect effects of silver nanoparticles on aquatic invertebrates
}

\author{
Yujia Zhai ${ }^{1}$. Nadja R. Brun ${ }^{1,2}$ - Mirco Bundschuh ${ }^{3,4}$ - Maarten Schrama ${ }^{1}$ - Eline Hin ${ }^{1}$. Martina G. Vijver ${ }^{1}$. \\ Ellard R. Hunting ${ }^{1,2,5}$
}

Received: 23 February 2018 / Accepted: 31 August 2018 / Published online: 14 September 2018

(c) The Author(s) 2018

\begin{abstract}
Complex natural systems are affected by multiple anthropogenic stressors, and therefore indirect effects within food webs are increasingly investigated. In this context, dead organic matter (OM) or detritus provides a food source sustaining detrital food webs that recycle the retained energy through microbial decomposition and invertebrate consumption. In aquatic environments, poorly water-soluble contaminants, including nanoparticles (NPs), quickly adsorb onto OM potentially modifying OM-associated microbial communities. Since invertebrates often depend on microbial conditioning to enhance OM quality, adverse effects on OM-associated microbial communities could potentially affect invertebrate performances. Therefore, this study assessed the effect of environmentally relevant concentrations of the model emerging contaminant, silver nanoparticles (AgNPs), on OM-associated microorganisms and subsequent indirect effects on growth of the invertebrate Asellus aquaticus. At low concentrations $(0.8 \mathrm{ug} / \mathrm{L})$, AgNPs inhibited activity and altered metabolic diversity of the OM-associated microbial community. This was observed to coincide with a negative effect on the growth of A. aquaticus due to antimicrobial properties, as a decreased growth was observed when offered AgNP-contaminated OM. When A. aquaticus were offered sterile OM in the absence of AgNPs, invertebrate growth was observed to be strongly retarded, illustrating the importance of microorganisms in the diet of this aquatic invertebrate. This outcome thus hints that environmentally relevant concentrations of AgNPs can indirectly affect the growth of aquatic invertebrates by affecting OM-associated microbial communities, and hence that microorganisms are an essential link in understanding bottom-up directed effects of chemical stressors in food webs.
\end{abstract}

Keywords Asellus aquaticus · Food web · Freshwater biofilms · Decomposition and consumption · Silver nanoparticles · Ecosystem functioning

Electronic supplementary material The online version of this article (https://doi.org/10.1007/s00027-018-0594-z) contains supplementary material, which is available to authorized users.

Ellard R. Hunting

e.r.hunting@bristol.ac.uk

1 Institute of Environmental Sciences (CML), Leiden University, P.O. Box 9518, 2300 RA Leiden, The Netherlands

2 Department of Biology, Woods Hole Oceanographic Institution, Woods Hole, MA, USA

3 Institute for Environmental Sciences, University of Koblenz-Landau, Fortstrasse 7, 76829 Landau, Germany

4 Department of Aquatic Sciences and Assessment, Swedish University of Agricultural Sciences, Lennart Hjelms väg 9, 75007 Uppsala, Sweden

5 School of Biological Sciences, University of Bristol, 24 Tyndall Avenue, Bristol BS8 1TQ, UK

\section{Introduction}

Dead organic matter (OM) or detritus serves as a major food source fueling aquatic detritivorous food webs. The nutrients and energy stored in OM are made available through decomposition mediated by microbial activity and invertebrate consumption (Webster and Benfield 1986; Gessner et al. 2010). Additionally, OM-associated microbial communities can partly degrade OM through enzymatic activity (known as conditioning), and therewith form an essential trophic link by stimulating invertebrate feeding (Graça 2001; Danger et al. 2012). OM-associated microorganisms positively affect growth and reproduction of many invertebrates relative to unconditioned food sources (Graça et al. 1993a, b), a benefit that relies on the provisioning of essential nutrients such as nitrogen, some fatty acids, and vitamins (e.g. Vonk et al. 2016). 
An increasing number of aquatic ecosystems are under continuous pressure from anthropogenic stressors (Goulson et al. 2014), fueling organismal research assessing direct lethal effects or molecular target pathways. Recently, efforts are increasingly directed towards assessing how contaminants can indirectly affect trophic interactions within food webs at sublethal, environmentally relevant concentrations (Holden et al. 2016; Schrama et al. 2017). Many contaminants that enter aquatic environments, including emerging compounds such as nanoparticles (NPs), are poorly soluble and therefore quickly adsorb to OM (Lu et al. 2014; Holsapple et al. 2005; Pradhan et al. 2016). Increasing evidence suggests that many such contaminants can have adverse effects on OM-associated microbial communities, with consequences for OM decomposition rates (e.g. Flores et al. 2014; Zubrod et al. 2011; Tlili et al. 2016; Du et al. 2018). Additionally, indirect effects on detritivorous food webs are possible. Pesticides, for instance, reduce OM consumption by several aquatic invertebrate species (e.g. Zubrod et al. 2015; Hunting et al. 2016), often driven by changes in the OM-associated microbial community (e.g. Feckler et al. 2016). However, while NPs were observed to negatively affect growth and diversity of OM-associated microbial communities (e.g. Tlili et al. 2016; Du et al. 2018; Pradhan et al. 2012; Batista et al. 2017a, b), bottom-up directed effects on detritivore growth remain unclear.

Many NPs have anti-microbial properties and the tendency to adsorb onto OM, and thus it can be hypothesized that NPs indirectly affect invertebrate growth by negatively affecting the OM-associated microbial communities (Holsapple et al. 2005; Pradhan et al. 2016; Fabrega et al. 2009; Du et al. 2018) or through the uptake of NPs as part of their food. We therefore assessed the effects of sub-lethal and environmentally relevant concentrations of silver nanoparticles (AgNPs) as a model emerging toxicant on (1) the activity and metabolic diversity of OM-associated microorganisms, and (2) the growth of the detritivore Asellus aquaticus in a well-controlled laboratory setting.

\section{Materials and methods}

\section{Study system}

Individuals of $A$. aquaticus were collected from ditches in the south-west of Netherlands (52 $\left.09^{\prime} 51.4^{\prime \prime} \mathrm{N} 4^{\circ} 27^{\prime} 55.3^{\prime \prime} \mathrm{E}\right)$ and sustained in a glass aquarium of $40 \times 25 \times 33 \mathrm{~cm}$ filled with a mixture of distilled water $\left(\mathrm{dH}_{2} \mathrm{O}\right)$ and ditch water $(2: 1$ $\mathrm{v} / \mathrm{v}$; aquarium water) and a layer $(1-2 \mathrm{~cm})$ of quartz sand under continuous aeration.

AgNPs with a nominal particle size of $15 \mathrm{~nm}$ were purchased from Nanostructured and Amorphous Materials (Houston, USA). Characterizations of the particle morphology of the AgNPs were performed using transmission electron microscopy (TEM) (JEOL 1010, IEOL Ltd., Japan) and dynamic light scattering (DLS) on a zetasizer Nano-ZS instrument (Malvern, Instruments Ltd., UK). Their physico-chemical characteristics of AgNPs during the early stages of the experiment are summarized in Table S1 and S2. AgNP's have a complex mode of toxic action, in which both AgNP's themselves and Ag ions in aquatic environments contribute to toxicity, often depending on various environmental conditions (Pradhan et al. 2011; Völker et al. 2013; Tlili et la. 2016; Zhai et al. 2016, 2017). Since this is difficult to disentangle within complex systems (e.g. natural $\mathrm{OM})$ and $\mathrm{AgNPs}$ were merely used to distort OM-associated microbial communities, contributions of AgNPs and ions were not assessed here.

DECOTABs were used as a surrogate OM to allow manipulation of AgNP concentrations (Kampfraath et al. 2012; Van der Lee 2018). In short, DECOTABs were prepared from $60 \mathrm{~g} / \mathrm{L}$ powdered organic hay serving as particulate $\mathrm{OM}(\mathrm{POM})$ and $20 \mathrm{~g} / \mathrm{L}$ purified agar (SigmaAldrich). An AgNP stock solution (1 g Ag/L) was sonicated $(38 \pm 10 \mathrm{kHz})$ for $8 \mathrm{~min}$ at $4{ }^{\circ} \mathrm{C}$ in a water bath to ensure a homogeneous dispersion of the particles (Zhai et al. 2016). Agar was dissolved in $\mathrm{dH}_{2} \mathrm{O}$ and heated up to $100{ }^{\circ} \mathrm{C}$. After cooling to below $50{ }^{\circ} \mathrm{C}$, POM was mixed together with AgNP with concentrations ranging 0.0, 0.2, 0.4, 0.8, 1.6, 3.2 and $6.4 \mu \mathrm{g} / \mathrm{L}$. Subsequently, the mixture was poured into the mold. Solidified DECOTABs were stored at $-20^{\circ} \mathrm{C}$. To measure the actual AgNP concentrations in the DECOTABs and the released $\mathrm{Ag}_{\text {(total) }}$ (AgNP and any other speciation of $\mathrm{Ag}$ ) from DECOTABs into the aquatic medium, DECOTABs were resuspended and digested in aqua regia $\left(\mathrm{HNO}_{3}\right.$ : $\mathrm{HCl}=1: 3$ ) at room temperature overnight followed by the evaporation of the acid at $70{ }^{\circ} \mathrm{C}$ and then resuspended in $3 \mathrm{~mL}$ of 5\% aqua regia. Also, water samples were acidified using 5\% aqua regia before measurements. The $\mathrm{Ag}_{\text {(total) }}$ concentrations in the AgNP-contaminated DECOTABs, as well as the $\mathrm{Ag}_{\text {(total) }}$ released from the $\mathrm{AgNP}$-contaminated DECOTABs into the aquatic medium, were determined 7 days after test initiation using Graphite Furnace Atomic Absorption Spectroscopy (GF-AAS; Perkin Elmer 1100B, The Netherlands). Actual $\mathrm{Ag}_{\text {(total }}$ concentrations within the AgNP-contaminated DECOTABs were determined in triplicate for the several concentrations (Table S3), and the percent of $\mathrm{Ag}_{\text {(total) }}$ released from the AgNP-contaminated DECOTABs into the aquatic test medium was max. $11 \%$ and increased with increasing AgNP concentration in the DECOTABs (Table S3).

\section{Experimental design}

To assess microbial metabolic diversity and activity, OMassociated microorganisms were grown on DECOTABs 
containing a range of AgNP concentrations (5 DECOTABs per concentration) as described above. DECOTABs were incubated in Petri-dishes filled with $40 \mathrm{~mL}$ aquarium water for 21 days. Afterwards the DECOTABs were vortexed for $30 \mathrm{~s}$ in $5 \mathrm{~mL} \mathrm{dH}_{2} \mathrm{O}$ to separate the developed biofilms from the DECOTABs, and the microbial metabolic diversity of the biofilms was measured using Ecoplates (Biolog, Hayward, CA, USA, Garland and Mills 1991). Ecoplates are microplates that contain 31 ecologically relevant carbon substrates, and the utilizations of the substrates reflects the metabolic potential of the tested microbial community. Although the actual functioning of the biofilm inherent microorganisms cannot be directly related to substrate utilization, the differences in the metabolic profiles can indicate the distinct effect of stressors (Hunting et al. 2015, 2017; Echavarri-Bravo et al. 2015). Therefore, the biofilms were diluted 30 times with $\mathrm{dH}_{2} \mathrm{O}$ (triplicate per replicate) and each well of the Ecoplates was inoculated with $50 \mu \mathrm{L}$ of the dilution at $20{ }^{\circ} \mathrm{C}$ for approximately $46 \mathrm{~h}$. After the incubation, optical density was measured at $600 \mathrm{~nm}$ using a BioTek microplate reader. Color development of substrates greater than 0.25 were included for assay evaluation as proposed by Garland and Mills (1991). The biofilms' Electron Transport System Activity (ETSA) as a proxy for bacterial activity was measured by determining spectrophotometrically the degradation of 2-(p-iodophenyl)-3-(p-nitrophenyl)-5-phenyl tetrazolium chloride to formazan at a wavelength of $490 \mathrm{~nm}$ according to Hunting et al. (2010).

To assess whether DECOTAB-associated microorganisms provide a nutritional source for the freshwater isopod $A$. aquaticus, DECOTABs without AgNPs were prepared for a second incubation. This procedure involved an additional set of DECOTABs, which served as a negative control. To this end, DECOTABs were kept sterile by placing them for $1 \mathrm{~h}$ in $70 \%$ ethanol followed by three times washing with $\mathrm{dH}_{2} \mathrm{O}$ and resting in $\mathrm{dH}_{2} \mathrm{O}$ for another $10 \mathrm{~min}$. Finally, one sterilized or conditioned DECOTAB was offered as food to $5 \mathrm{~A}$. aquaticus (average $0.17 \mathrm{~cm}$ in length) in Petri-dishes filled with $40 \mathrm{~mL}$ aquarium water for 28 days. Both treatments were run in duplicate. Sterile DECOTABs were refreshed every other day, while conditioned DECOTABs were refreshed every 5 days. Every seven days, individual A. aquaticus were imaged using eScope (v. 1.1.7.17) and body length measured using ImageJ (v. 1.51j8).

The third series of incubations assessed direct and indirect (food quality related) effects of AgNPs on the microbial metabolic diversity and activity, as well as the growth of the freshwater isopod A. aquaticus as described above. DECOTABs containing different AgNP concentrations (see above) were offered as food to $5 \mathrm{~A}$. aquaticus (average $0.17 \mathrm{~cm}$ in length) in Petri-dishes filled with $40 \mathrm{~mL}$ aquarium water for 35 days. DECOTABs were refreshed every 5 days. Due to a constraint in the number of isopod offspring, the experiment was split up into two sequential runs using independent juvenile $A$. aquaticus individuals, in which each treatment was run in duplicates. This finally resulted in 4 independent replicates per treatment. Microbial metabolic diversity and activity were assessed after 21 days as described above. Every 7 days, individuals of $A$. aquaticus were imaged using eScope (v. 1.1.7.17) and body length was measured using ImageJ (v. 1.51j8).

\section{Statistical analysis}

Differences in Ecoplate (Biolog) substrate utilization between different AgNP treatments were analyzed using a Gower-based cluster analysis and a one-way analysis of similarities (ANOSIM) using PAST 3.0 to determine the bacterial functional composition (Hammer et al. 2001; Villéger et al. 2008). Isopod growth was assessed by measuring the mean increase in growth of the 5 pseudo-replicates within 1 replicate Petri-dish. Microbial activity and isopod growth were assessed in relation to increasing concentrations of AgNPs by non-linear and linear least square regression, respectively.

\section{Results}

\section{Metabolic diversity and activity of OM-associated microorganisms}

The metabolic diversity of the microbial biofilms that developed on the DECOTABs were assessed by substrate utilizations under different AgNP treatments (Fig. 1). The microbial communities in the control were in general able to metabolize 14 of the 31 carbon sources, and the utilization of most of the substrates decreased with the increasing concentrations of the AgNPs. Cluster analysis showed a clear clustering of AgNP treatments; microbial metabolic potential differed significantly (one-way ANOSIM: $R=0.919$, $p<0.05$ ) (Fig. 1). Furthermore, metabolic diversity of the DECOTAB-associated biofilm is expressed as average well colour development (AWCD; Figure S1, Supplementary Data), indicating a decreased metabolic diversity with increasing AgNP concentration.

The effect of AgNPs on the activity of microorganisms within biofilms developed on the DECOTABs is provided in Fig. 2. Microbial activity decreased exponentially with increasing concentrations of AgNPs.

\section{Growth of A. aquaticus}

Juveniles fed on sterilized DECOTABs exhibited a significantly smaller increase in body length compared to the juveniles fed on conditioned DECOTABs $\left(\mathrm{F}_{(1,8)} 51,6, \mathrm{P}<0.0001\right.$; 


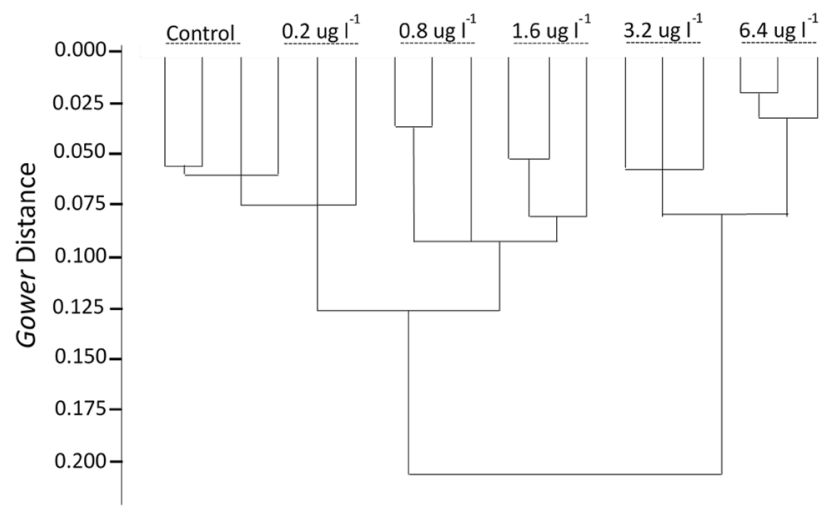

Fig. 1 Cluster analysis of the metabolic diversity of bacterial communities under increasing AgNP concentrations. Clustering according to the Ecoplate (Biolog) substrate utilization patterns by OM-associated microbial communities (one-way ANOSIM, Gower-based similarity, $\left.n=3, R^{2}=0.919, p<0.05\right)$

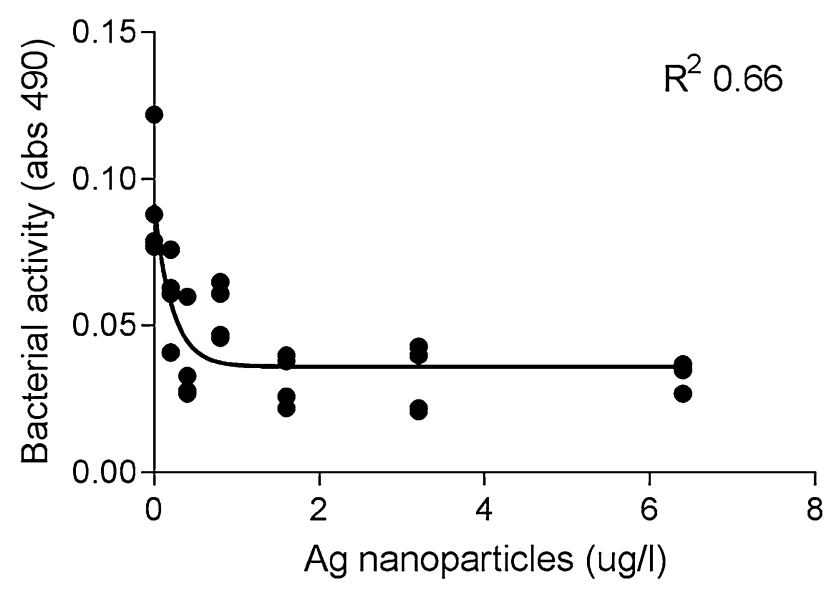

Fig. 2 Microbial activity of the DECOTAB-associated biofilm with increasing AgNP concentration (measured at abs. $490 \mathrm{~nm}$ ). Fitted line represents an exponential decay function; goodness of fit (adjusted $R^{2}$ ) is shown in the figure
Fig. 3), with almost no growth over the entire test period in the animals feeding on the sterilized DECOTABs (Fig. 3). In general, weekly measurements of the juveniles revealed an exponential growth during the 28-day period (Figure S2, Supplementary Data), but the addition of AgNPs had an overall negative effect on A. aquaticus growth over the course of the experiment (Fig. 4), where nominal concentrations $\geq 0.8 \mathrm{ug} / \mathrm{L}$ were significantly different to the control $(p<0.05)$.

\section{Discussion}

This study used AgNPs as a model emerging toxicant to illustrate indirect affects on the growth of an aquatic invertebrate via adverse effects on the metabolic activities of OMassociated microbial communities. The metabolic activity of the OM-associated microorganisms was negatively affected by AgNP at low and environmentally relevant concentrations with a decline in microbial activity and metabolic diversity with increasing AgNP concentration. Ag ions and AgNPs are known to generate reactive oxygen species causing damage to mitochondrial respiratory function, hyperoxidation of lipids, and proteins (Morones et al. 2005; Pal et al. 2007; Sillen et al. 2015; Dakal et al. 2016), and the observed reduction in metabolic activity likely points to a disruption in electron transport chains in both cell membranes or extracellular matrix (Trevors 1984; Hunting et al. 2015). OMassociated AgNP contamination thus constrains metabolic diversity and retards microbial respiratory activity, which itself may already retard microbial-mediated OM degradation (Tlili et al. 2016).

Microorganisms are considered an important diet of macro-invertebrates (Graça et al. 1993ab; Chung and Suberkropp 2009), supporting their growth (Findlay and Tenore 1982; Findlay et al. 1984). This observation is also supported during the present study documenting only low growth rates of $A$. aquaticus when fed with sterile relative to conditioned
Fig. 3 Growth of A. aquaticus feeding on sterile (dotted line) and conditioned (solid line) DECOTABs, in which both treatments differ significantly in their slopes ( $t$-test, $p<0.01)$. Goodness of fits and significances are presented for both treatments

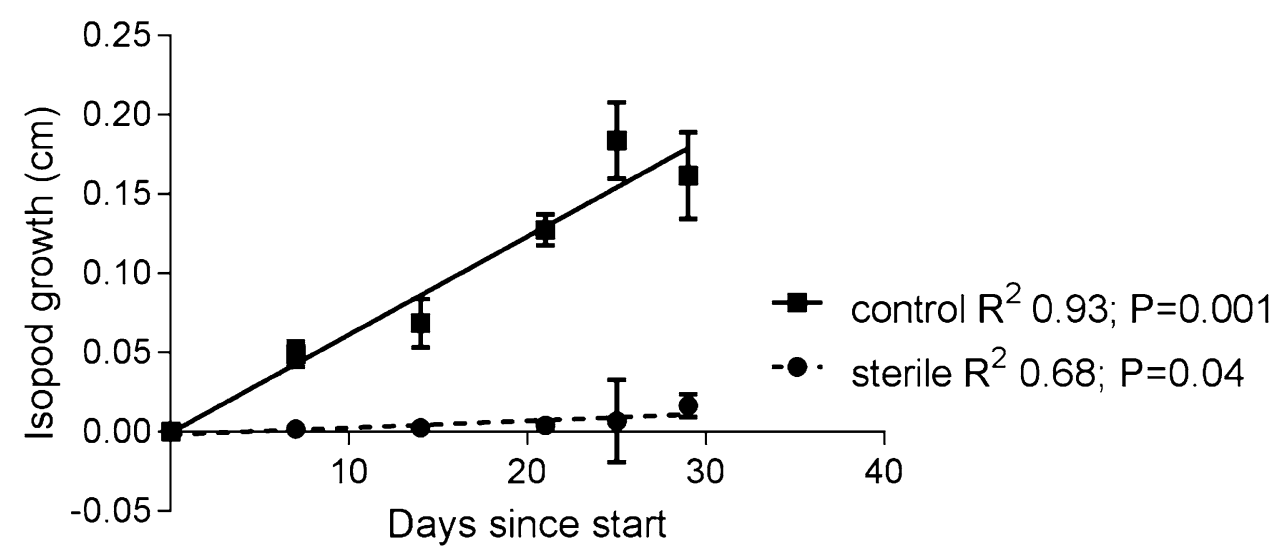




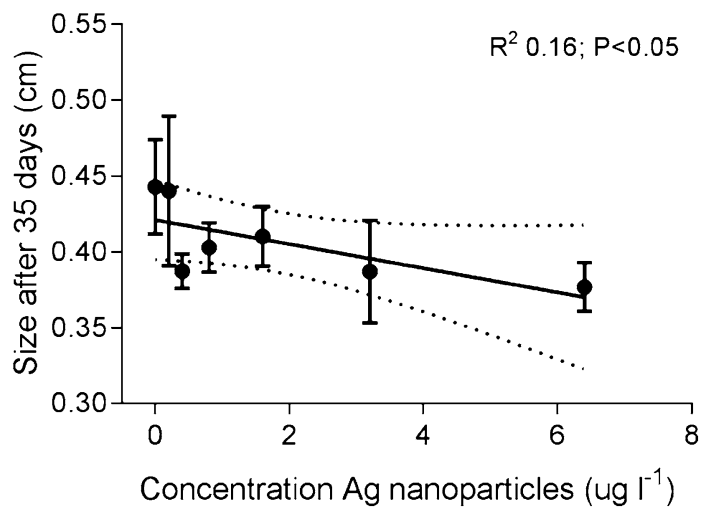

Fig. 4 Isopod size after 35 days of juvenile A. aquaticus individuals. Solid fit represents a linear regression, dotted lines represent $95 \%$ confidence intervals. $x$-axis represents nominal AgNP concentrations within DECOTABs

DECOTABs. Traditionally, the potential beneficial role of microorganism is attributed to their ability to decompose structural polysaccharides in OM such as leaf litter thereby reducing its toughness as well as by increasing nutritious values by concentrating essential nutrients, amino and fatty acids (Graça 2001; Danger et al. 2012). Since agar cannot be degraded by most organisms, the degradation of polysaccharides unlikely played a role, illustrating the importance of microorganisms for life history strategy (i.e., growth) of A. aquaticus. These observations point towards an even higher relevance of OM-associated microbes (here presumably mainly bacteria) for some leaf shredding invertebrates than previously anticipated (Chung and Suberkropp 2009).

Here we observed indirect effects of NPs in a simplified detrital food chain considering interactions between two trophic levels. Even at low concentrations, adverse effects of AgNPs on microorganisms were observed to coincide with a reduced growth of A. aquaticus. Likewise, adverse sub-lethal effects of OM-contamination with pesticides affected OM consumption for several aquatic invertebrate species (e.g. Flores et al. 2014; Zubrod et al. 2015; Hunting et al. 2016; Feckler et al. 2016). As commonly observed with metal NPs (Pradhan et al. 2012), we found a $1-11 \%$ release of silver ions from the $\mathrm{OM}$ towards the surrounding water, depending on the concentrations of AgNPs in the DECOTABs (Table S3). It is likely that waterborne metals adsorb and accumulate in leaves and OM, as observed for CuNP (Pradhan et al. 2012), and therewith fuel the dietary toxicity towards invertebrates. Overall, the waterborne concentrations were low and typically do not elicit direct effects (Baptista et al. 2015; Mckee et al. 2016), however, we cannot rule out the possibility of waterborne Ag ions contributing to the impairments in A. aquaticus growth. Likewise, ingestion of OM containing AgNP may have contributed to growth impairment. Despite this, results presented here suggest that OM-associated AgNPs also can have microbiallymediated effects on the performances of aquatic invertebrates. Since contamination of food items and its inherent trophic interactions seem more subtle and sensitive than test organisms typically used to assess toxicity, our results indicate that contamination of OM with AgNPs is a relevant exposure route to consider when assessing realistic effects of NPs in the aquatic environment.

This study shows that AgNPs can inhibit the activity and alter metabolic diversity of OM-associated microbial communities and that this can coincide with a negative effect on the growth of A. aquaticus. Impaired growth rates may have wider implications for aquatic food webs as less biomass will be available for predatory invertebrates and fish (e.g. Rask and Hiisivuori 1985; Krisp and Maier 2005). While direct toxicity is typically observed at high AgNP concentrations (Zhao and Wang 2011; Topuz and Van Gestel 2015; Baptista et al. 2015; Mckee et al. 2016), we observed low AgNP-concentration effects on microbial communities to translate to invertebrate growth effects. This calls for further investigations and consideration of trophic interactions assessing hazards and risks of NPs for the environment. Since effects observed on a realistic exposure pathway were caused by an AgNP concentration in the $\mathrm{ng} / \mathrm{L}$ range, the observed trophic cascade poses concerns provided the effective AgNP concentrations fall within existing estimates of current environmental concentrations (Gottschalk et al. 2013).

Acknowledgements The Chinese Scholarship Council (CSC) is gratefully acknowledged for its financial support to Yujia Zhai [201506510003]. Martina G. Vijver is funded by NWO-VIDI [project number 864.13.010].

Open Access This article is distributed under the terms of the Creative Commons Attribution 4.0 International License (http://creativeco mmons.org/licenses/by/4.0/), which permits unrestricted use, distribution, and reproduction in any medium, provided you give appropriate credit to the original author(s) and the source, provide a link to the Creative Commons license, and indicate if changes were made.

\section{References}

Baptista MS, Miller RJ, Halewood ER, Hanna SK, Almeida CM, Vasconcelos VM, Keller AA, Lenihan HS (2015) Impacts of silver nanoparticles on a natural estuarine plankton community. Environ Sci Technol 49:12968-12974

Batista D, Pascoal C, Cássio F (2017a) How do physicochemical properties influence the toxicity of silver nanoparticles on freshwater decomposers of plant litter in streams? Ecotoxicol Environ Safe 140:148-155

Batista D, Pascoal C, Cássio F (2017b) Temperature modulates AgNP impacts on microbial decomposer activity. Sci Total Environ 601-602:1324-1332 
Bundschuh M, Seitz F, Rosenfeldt RR, Schulz R (2016) Effects of nanoparticles in fresh waters: Risks, mechanisms and interactions. Freshw Biol 61:2185-2196

Chung N, Suberkropp K (2009) Contribution of fungal biomass to the growth of the shredder, Pycnopsyche gentilis (Trichoptera: Limnephilidae). Freshw Biol 54(11):2212-2224

Croteau M-N, Misra SK, Luoma SN, Valsami-Jones E (2011) Silver bioaccumulation dynamics in a freshwater invertebrate after aqueous and dietary exposures to nanosized and ionic Ag. Environ Sci Technol 45:6600-6607

Dakal TC, Kumar A, Majumdar RS, Yadav V (2016) Mechanistic basis of antimicrobial actions of silver nanoparticles. Front Microbiol $7: 1831$

Danger M, Cornut J, Elger A, Chauvet E (2012) Effects of burial on leaf litter quality, microbial conditioning and palatability to three shredder taxa. Freshw Biol 57:1017-1030

Delay M, Dolt T, Woellhaf A, Sembritzki R, Frimmel FH (2011) Interactions and stability of silver nanoparticles in the aqueous phase: influence of natural organic matter (NOM) and ionic strength. J Chromatogr A 1218:4206-4212

Doiron K, Pelletier E, Lemarchand K (2012) Impact of polymer-coated silver nanoparticles on marine microbial communities: a microcosm study. Aquat Toxicol 124-125:22-27

Du J, Zhang Y, Guo W, Li N, Gao C, Cui M, Lin Z, Wei M, Zhang H (2018) Chronic impacts of $\mathrm{TiO}_{2}$ nanoparticles on Populus nigra L. leaf decomposition in freshwater ecosystem. J Hazard Mater 350:121-127

Echavarri-Bravo V, Paterson L, Aspray TJ, Porter JS, Winson MK, Thornton B, Hartl MGJ (2015) Shifts in the metabolic function of a benthic estuarine microbial community following a single pulse exposure to silver nanoparticles. Environ Pollut 201:91-99

Fabrega J, Fawcett SR, Renshaw JC, Lead JR (2009) Silver nanoparticle impact on bacterial growth: effect of $\mathrm{pH}$, concentration, and organic matter. Environ Sci Technol 43:7285-7290

Fabrega J, Luoma SN, Tyler CR, Galloway TS, Lead JR (2011) Silver nanoparticles: behaviour and effects in the aquatic environment. Environ Int 2:517-531

Feckler A, Goedkoop W, Zubrod JP, Schulz R, Bundschuh M (2016) Exposure pathway-dependent effects of the fungicide epoxiconazole on a decomposer-detritivore system. Sci Total Environ 571:992-1000

Findlay S, Tenore K (1982) Nitrogen source for a detritivore: detritus substrate versus associated microbes. Science 218:15-17

Findlay S, Meyer JL, Smith PJ (1984) Significance of bacterial biomass in the nutrition of a freshwater isopod (Lirceus sp.). Oecologia 63:38-42

Flores L, Banjac Z, Farré M, Larranaga A, Mas-Marti E, Munoz I, Barceló D, Elosegi A (2014) Effects of a fungicide (imazalil) and an insecticide (diazinon) on stream fungi and invertebrates associated with litter breakdown. Sci Total Environ 476:532-541

Garland JL, Mills AL (1991) Classification and characterization of heterotrophic microbial communities on the basis of patterns of community-level sole-carbon-source utilization. Appl Environ Microb 57:2351-2359

Gessner MO, Swan CM, Dang CK, McKie BG, Bardgett RD, Wall DH, Hättenschwiler S (2010) Diversity meets decomposition. Trends Ecol Evol 25:372-380

Gottschalk F, Sun T, Nowack B (2013) Environmental concentrations of engineered nanomaterials: review of modeling and analytical studies. Environ Pollut 181:287-300

Goulson D (2014) Pesticides linked to bird declines. Nature 511:295-296

Graça MA (2001) The role of invertebrates on leaf litter decomposition in streams-a review. Int Rev Hydrobiol 86:383-393
Graça MAS, Maltby L, Calow P (1993a) Importance of fungi in the diet of Gammarus pulex and Asellus aquaticus $\mathrm{I}$ : feeding strategies. Oecologia 93:139-144

Graça MAS, Maltby L, Calow P (1993b) Importance of fungi in the diet of Gammarus pulex and Asellus aquaticus. Oecologia 96:304-309

Hammer Ø, Harper DAT, Ryan PD (2001) PAST: Paleontological statistics software package for education and data analysis. Palaeontol Electron 4:9

Holden PA, Gardea-Torresdey JL, Klaessig F, Turco RF, Mortimer M, Hund-Rinke K, Hubal C, Avery EA, Barceló D, Behra D, Cohen R, Deydier-Stephan Y, Ferguson L, Fernandes PL, Harthorn TF, Henderson BH, Hoke WM, Hristozov RA, Johnston D, Kane JM, Kapustka AB, Keller L, Lenihan AA, Lovell HS, Murphy W, Nisbet CJ, Petersen RM, Salinas EJ, Scheringer ER, Sharma M, Speed M, Sultan DE, Westerhoff Y, White P, Wiesner JC, Wong MR, Xing EM, Horan B, Godwin MS, Nel HA, A.E (2016) Considerations of environmentally relevant test conditions for improved evaluation of ecological hazards of engineered nanomaterials. Environ Sci Technol 50:6124-6145

Holsapple MP, Farland WH, Landry TD, Monteiro-Riviere NA, Carter JM, Walker NJ, Thomas KV (2005) Research strategies for safety evaluation of nanomaterials, part II: toxicological and safety evaluation of nanomaterials, current challenges and data needs. Toxicol Sci 88:12-17

Hunting ER, De Goeij JM, Asselman M, Van Soest RWM, Van Der Geest HG (2010) Degradation of mangrove-derived organic matter in mangrove associated sponges. Bull Mar Sci 86:871-877

Hunting ER, Vijver MG, van der Geest HG, Mulder C, Kraak MHS, Breure AM, Admiraal W (2015) Resource niche overlap promotes stability of bacterial community metabolism in experimental microcosms. Fron Microbiol 6:105

Hunting ER, Vonk JA, Musters CJM, Kraak MH, Vijver MG (2016) Effects of agricultural practices on organic matter degradation in ditches. Sci Rep 6:21474

Hunting ER, Barmentlo SH, Schrama M, van Bodegom PM, Zhai Y, Vijver MG (2017) Agricultural constraints on microbial resource use and niche breadth in drainage ditches. PeerJ 5:e4175

Kampfraath AA, Hunting ER, Mulder C, Breure AM, Gessner MO, Kraak MHS, Admiraal W (2012) DECOTAB-a multipurpose standard substrate to assess litter quality effects on microbial decomposition and invertebrate consumption. Freshw Sci 31:1156-1162

Krisp H, Maier G (2005) Consumption of macroinvertebrates by invasive and native gammarids: a comparison. J Limnol 64(1):55-59

Lu YH, Bauer JE, Canuel EA, Chambers RM, Yamashita Y, Jaffé R, Barrett A (2014) Effects of land use on sources and ages of inorganic and organic carbon in temperate headwater streams. Biogeochemistry 119:275-292

McKee MS, Engelke M, Zhang X, Lesnikov E, Köser J, Eickhorst T, Filser J (2016) Collembola reproduction decreases with aging of silver nanoparticles in a sewage sludge-treated soil. Front Environ Sci 5:19

Morones JR, Elechiguerra JL, Camacho A, Holt K, Kouri JB, Ramírez JT, Yacaman MJ (2005) The bactericidal effect of silver nanoparticles. Nanotechnology 16(10):2346

Pal S, Tak YK, Song JM (2007) Does the antibacterial activity of silver nanoparticles depend on the shape of the nanoparticle? A study of the gram-negative bacterium Escherichia Coli. Appl Environ Microbiol 73:1712-1720

Pradhan A, Seena S, Pascoal C, Cássio F (2011) Can metal nanoparticles be a threat to microbial decomposers of plant litter in streams? Microb Ecol 62(1):58-56 
Pradhan A, Seena S, Pascoal C, Cássio F (2012) Copper oxide nanoparticles can induce toxicity to the freshwater shredder Allogamus ligonifer. Chemosphere 89(9):1142-1150

Pradhan A, Geraldes P, Seena S, Pascoal C, Cássio F (2016) Humic acid can mitigate the toxicity of small copper oxide nanoparticles to microbial decomposers and leaf decomposition in streams. Freshw Biol 61:2197-2210

Rask M, Hiisivuori C (1985) The predation on Asellus aquaticus (L.) by perch, Perca fluviatilis (L.), in a small forest lake. Hydrobiologia 121(1):27-33

Schrama M, Barmentlo SH, Hunting ER, Van Logtestijn R, Vijver MG, Van Bodegom PM (2017) Pressure-induced shifts in trophic linkages in a simplified aquatic food web. Front Environ Sci 5:75

Sillen WMA, Thijs S, Abbamondi GR, Janssen J, Weyens N, White JC, Vangronsveld J (2015) Effects of silver nanoparticles on soil microorganisms and maize biomass are linked in the rhizosphere. Soil Biol Biochem 91:14-22

Song L, Connolly M, Fernández-Cruz ML, Vijver MG, Fernández M, Conde E, de Snoo GR, Peijnenburg WJGM, Navas JM (2014) Species-specific toxicity of copper nanoparticles among mammalian and piscine cell lines. Nanotoxicology 8:383-393

Tlili A, Cornut J, Behra R, Gil-Allué C, Gessner MO (2016) Harmful effects of silver nanoparticles on a complex detrital model system. Nanotoxicology 10:728-735

Topuz E, Van Gestel CAM (2015) Toxicokinetics and toxicodynamics of differently coated silver nanoparticles and silver nitrate in Enchytraeus Crypticus upon aqueous exposure in an inert sand medium. Environ Toxicol Chem 9999:1-8

Trevors JT (1984) The measurement of electron transport system (ETS) activity in freshwater sediment. Water Res 18:581-584

Villéger S, Mason NWH, Mouillot D (2008) New multidimensional functional diversity indices for a multifaceted framework in functional ecology. Ecology 89:2290-2301

Völker C, Oetken M, Oehlmann J (2013) The biological effects and possible modes of action of nanosilver. Rev Environ Contam Toxicol 233:81-106
Vonk JA, Van Kuijk BF, Van Beusekom M, Hunting ER, Kraak MH (2016) The significance of linoleic acid in food sources for detritivorous benthic invertebrates. Sci Rep 6:35785

Webster JR, Benfield EF (1986) Vascular plant breakdown in freshwater ecosystems. Ann Rev Ecol Syst 17:567-594

Whittaker RJ, Rigal F, Borges PA, Cardoso P, Terzopoulou S, Casanoves F, Triantis KA (2014) Functional biogeography of oceanic islands and the scaling of functional diversity in the Azores. Proc Natl Acad Sci USA 111:13709-13714

Zak JC, Willig MR, Moorhead DL, Wildman HG (1994) Functional diversity of microbial communities: a quantitative approach. Soil Biol Biochem 26:1101-1108

Zhai Y, Hunting ER, Wouters M, Peijnenburg WJGM, Vijver MG (2016) Silver nanoparticles, ions, and shape governing soil microbial functional diversity: nano shapes micro. Front Microbiol 7:1123

Zhai Y, Hunting ER, Wouterse M, Peijnenburg WJ, Vijver MG (2017) Importance of exposure dynamics of metal-based nano- $\mathrm{ZnO},-\mathrm{Cu}$ and- $\mathrm{Pb}$ governing the metabolic potential of soil bacterial communities. Ecotoxicol Environ Saf 145:349-358

Zhao C-M, Wang W-X (2011) Comparison of acute and chronic toxicity of silver nanoparticles and silver nitrate to Daphnia magna. Environ Toxicol Chem 30:885-892

Zubrod JP, Bundschuh M, Feckler A, Englert D, Schulz R (2011) Ecotoxicological impact of the fungicide tebuconazole on an aquatic decomposer-detritivore system. Environ Toxicol Chem 30:2718-2724

Zubrod JP, Englert D, Wolfram J, Wallace D, Schnetzer N, Baudy P, Konschak M, Schulz R, Bundschuh M (2015) Waterborne toxicity and diet-related effects of fungicides in the key leaf shredder Gammarus fossarum (Crustacea: Amphipoda). Aquat Toxicol 169:105-112 